OPEN ACCESS

Edited by:

Esther Lutgens,

Academic Medical

Center, Netherlands

Reviewed by:

Cécile Oury

University of Liège, Belgium

Helen E. Collins,

University of Louisville, United States

*Correspondence:

Jianhui Rong

jrong@hku.hk

Specialty section:

This article was submitted to

Atherosclerosis and Vascular

Medicine

a section of the journa

Frontiers in Cardiovascular Medicine

Received: 28 April 2021

Accepted: 01 July 2021

Published: 28 July 2021

Citation:

Zhao W, Zhang X and Rong J (2021)

SUMOylation as a Therapeutic Target

for Myocardial Infarction.

Front. Cardiovasc. Med. 8:701583.

doi: 10.3389/fCVm.2021.701583

\section{SUMOylation as a Therapeutic Target for Myocardial Infarction}

\author{
Wei Zhao ${ }^{1,2}$, Xiuying Zhang ${ }^{1}$ and Jianhui Rong ${ }^{1,3 *}$ \\ ${ }^{1}$ Li Ka Shing Faculty of Medicine, School of Chinese Medicine, University of Hong Kong, Hong Kong, China, ${ }^{2}$ Zhujiang \\ Hospital, Southern Medical University, Guangzhou, China, ${ }^{3}$ Shenzhen Institute of Research and Innovation, The University of \\ Hong Kong, Shenzhen, China
}

Myocardial infarction is a prevalent and life-threatening cardiovascular disease. The main goal of existing interventional therapies is to restore coronary reperfusion while few are designed to ameliorate the pathology of heart diseases via targeting the post-translational modifications of those critical proteins. Small ubiquitin-like modifier (SUMO) proteins are recently discovered to form a new type of protein post-translational modifications (PTM), known as SUMOylation. SUMOylation and deSUMOylation are dynamically balanced in the maintenance of various biological processes including cell division, DNA repair, epigenetic transcriptional regulation, and cellular metabolism. Importantly, SUMOylation plays a critical role in the regulation of cardiac functions and the pathology of cardiovascular diseases, especially in heart failure and myocardial infarction. This review summarizes the current understanding on the effects of SUMOylation and SUMOylated proteins in the pathophysiology of myocardial infarction and identifies the potential treatments against myocardial injury via targeting SUMO. Ultimately, this review recommends SUMOylation as a key therapeutic target for treating cardiovascular diseases.

Keywords: myocadial infarction, sumoylation, sumoylated proteins, small ubiquitin-like modifier, myocardial ischemia-reperfusion injury

\section{INTRODUCTION}

Cardiovascular diseases have recently become a leading contributor to the burden to the global health care systems and economy (1). Myocardial infarction (MI) jeopardizes the health and life of more than 7 million individuals worldwide each year, $\sim 550,000$ first episodes and 200,000 recurrent episodes (2). Upon MI, sudden ischemia causes myocardial necrosis, heart failure, and even cardiac arrest (3). The existing interventional coronary reperfusion strategies are effective in controlling morbidity and mortality of MI. However, novel therapies are pressingly needed to increase the survival rate and reduce the re-occurrence of MI. The current effort is directed to the development of new drugs for the treatment of heart failure (4). On the other hand, effective medicines are also needed to halt disease progression and promote the recovery of cardiac functions.

It is well-known that some proteins fail to function properly and others become hyperactivated in heart diseases due to the dysregulation of protein post-translational modifications (PTM) including phosphorylation, acetylation, glycosylation, amidation, hydroxylation, methylation, ubiquitylation and sulfation $(5,6)$. These PTMs are dynamically balanced by conjugation and de-conjugation by functionally opposing enzymes. Indeed, PTMs are crucial for adapting various signaling pathways to maintain cellular homeostasis and adapt the cells to various stress stimuli (7). 
Among different PTMs, SUMOylation describes that a family of five small ubiquitin-like modifier (SUMO) proteins, namely SUMO1-5, form covalent and reversible conjugates with selected proteins and thereby regulates various cellular processes and functions $(8,9)$. During the SUMOylation, the SUMO proteins are proteolytically cleaved by SUMO/sentrin-specific protease (SENP) to yield the mature form of SUMOs. Subsequently, the SUMO E1 enzyme (SAE1/SAE2) activates the matured SUMOs while the SUMO E2 conjugating enzyme (UBC9) catalyzes the conjugation. Furthermore, the SUMO E3 ligase catalyzes the SUMOylation by transferring SUMOs to the target proteins. On the other hand, the SUMOylated proteins undergo deconjugation by SENP via dissociating the target protein-SUMO conjugates. Under physiological conditions, SUMOylation and deSUMOylation are dynamically balanced as shown in Figure $\mathbf{1}$. By contrast, the imbalance between SUMOylation and deSUMOylation is implicated in cardiac diseases (10-12). Previous studies focused on the role of SUMOylation in heart failure $(8,13)$. For instance, a small molecule N106 was used to target SERCA2a SUMOylation as a potential treatment for heart failure (8). Interestingly, exosomes were isolated from fibroblasts in heart failure and might deliver miR-146 to reduce SUMO1 expression in cardiac myocytes (14). However, the roles of SUMOylation in MI have not been fully examined.

This review aims to update the current knowledge on the role of SUMOylation and SUMOylated proteins in the pathology and cardiac repair of MI. Previous studies have reported some SUMOylation proteins as targets for the treatment of MI (1517). Thus, this review discussed the effects of the SUMOylation on the subcellular location of these protein targets and the progression of MI and overview the functions and clinical application stages of protein SUMOylation. We would highlight the SUMO machinery as a potential therapeutic target for drug discovery against MI injury.

\section{PROCESS OF PROTEIN SUMOYLATION}

\section{The Family of SUMO Proteins}

The first isoform of SUMO proteins was identified as sentrin in 1996 (18). Sentrin is demonstrated to form a covalent conjugate with proteins by attaching SUMO to specific lysine residue and regulate protein functions, suggesting a novel PTM mechanism $(19,20)$. Thus, SUMOylation is proposed to describe the modification process of various proteins via reversibly attaching to the lysine residues through a multi-step enzymatic reaction cascade (Figure 1).

To date, five SUMO isoforms (SUMO1, 2, 3, 4, and 5) have been identified (21). SUMO1 and $2 / 3$ are widely distributed in the body, whereas SUMO4 and SUMO5 appear to be tissuespecific and less investigated though. The SUMO4 was only found

\footnotetext{
Abbreviations: MI, myocardial infarction; SUMO, small ubiquitin-like modifier; PTM, post-translational modifications; SENP, sentrin-specific protease; MI/R, myocardial ischemia-reperfusion; PPAR, peroxisome proliferator activated receptor; HDAC, histone deacetylase; Sirtuin 1, silent information regulator 1; HIF-1 $\alpha$, hypoxia-inducible factor-1 $\alpha$; Drp 1, dynamin-related protein 1; SERCA2a, sarcoplasmic reticulum $\mathrm{Ca}^{2+}$ ATPase pump; FXR, farnesoid-Xreceptor; PIAS1, protein inhibitor of activated STAT1.
}

in the kidney, spleen, and lymph nodes (9). What we know so far: SUMO4 is discovered as an intron-free pseudogene in the study of single nucleotide polymorphism in type 1 diabetes (22). As a recently discovered family member, SUMO5 was identified in primates and showed high tissue specificity and might be involved in the regulation of promyelocytic leukemia nuclear bodies $(21,23)$. Based on the primary structure, SUMO1 shows $48 \%$ sequence identity with both SUMO2 and SUMO3, while the latter two isoforms are highly similar and with $97 \%$ of identity (24). SUMO4 shares $85 \%$ identity with SUMO2/3 although no evidence supports the conjugation with substrates $(4,22)$. The SUMO5 is highly homologous to SUMO1 (25). On the other hand, SUMOylation occurs at selective lysine residue within the canonical/consensus motif of $\Phi$-K-X-E/D, known as SUMOinteracting motif (SIM), where $\Phi$ is a hydrophobic residue, $\mathrm{K}$ is lysine for SUMO to form conjugate, $\mathrm{X}$ is any amino acid residue, and $\mathrm{E} / \mathrm{D}$ is an acidic residue (26).

Nevertheless, SUMO isoforms have overlapping functions and may compensate each other under certain circumstances.

\section{Dynamic Balance Between SUMOylation and deSUMOylation}

SUMOylation and deSUMOylation are dynamically balanced under physiological conditions. As shown in Figure 1, SUMOylation describes the covalent modification of protein substrates by SUMOs while deSUMOylation removes SUMOs from SUMOylated proteins. The SUMO proteases in the SUMO pathway are listed in Table 1. For forming covalent conjugates with protein substrates, SUMOs undergo maturation via proteolytic cleavage of the C-terminal Glycin -Glycin ( $\sim \mathrm{GG})$ dipeptide by SENP (28). SUMOs are attached to protein substrates through three reaction steps: ATP-dependent activation, SUMO- E2(UBC9) conjugation, and SUMO-protein substrate ligation. Firstly, the mature SUMO is activated by the E1 activating enzyme (SAE1/2) in an ATP-dependent manner. Secondly, the E2 conjugating enzyme UBC9 takes over SUMO moiety via forming covalent conjugate. Finally, the E3 ligase brings protein substrate and E2/UBC9 SUMO complex into the closer proximity and yields the covalent conjugate of the SUMOylated proteins including a protein inhibitor of activated STAT (PIAS) family, RanBR2, polycomb2, mitochondrialanchored protein ligase (MAPL), and much other protein substrates $(20,29)$.

The deSUMOylation describes the removal of SUMO moiety from target proteins by the SENP and deSUMOylating isopeptidases $(19,30)$. The SENP family includes six members, namely SENP 1-3, 5-7 in humans. Different SENP members act on specific SUMOylated proteins (31). SENP1 and SENP2 catalyze the deSUMOylation of all types of SUMO proteins (32), whereas SENP3, 5, 6, and 7 prefer SUMO2/3-derived SUMOylated proteins $(33,34)$. Ultimately, deSUMOylation eliminates the effects of SUMOylation on protein functions (35).

SUMOylation plays important role in the various molecular events and processes (36). First, SUMOylation may promote or block the association of molecules that interact with 


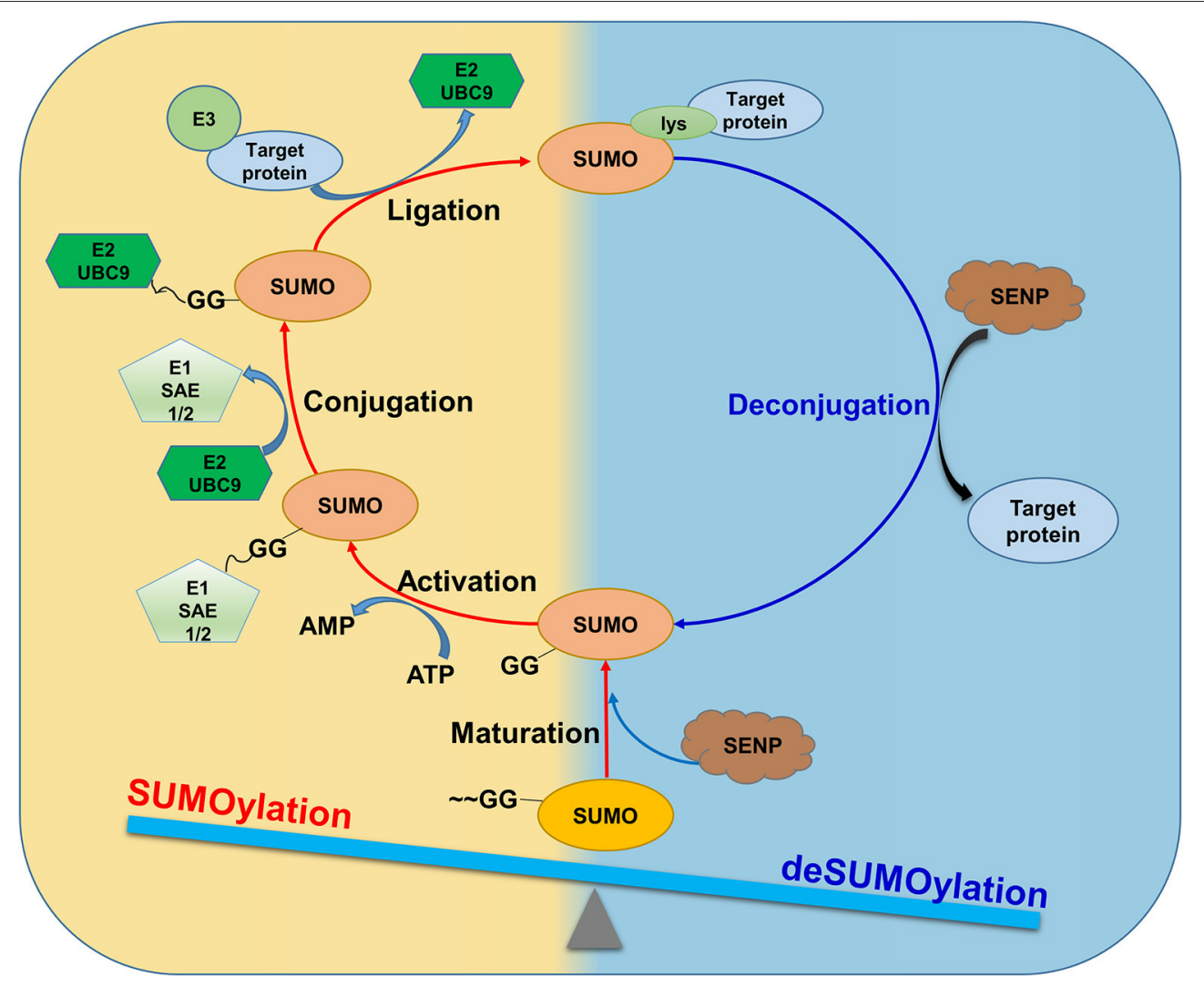

FIGURE 1 | SUMOylation and deSUMOylation are dynamically balanced under physiological conditions. SUMO proteins are proteolytically cleaved by SUMO/ SENP to form mature forms. The matured SUMOs are activated by SAE1/SAE2 in an ATP-dependent manner. E2 UBC9 catalyzes the transesterification to form E2 UBC9 conjugate while the SUMO E3 ligase catalyzes the SUMOylation by transferring SUMOs to the target protein at the specific lysine residues. On the other hand, the SUMOylated proteins undergo deconjugation to dissociate the target protein-SUMO conjugates by SENP. Under physiological conditions, SUMOylation and deSUMOylation are dynamically balanced.

SUMOylated substrates. Vivek et al. showed that SUMOylation mediated WRKY33 phosphorylation while disruption of WRKY33 SUMO sites inactivated WRKY33-mediated defense (37). Waizenegger et al. found that Mms4 was engaged by (poly)SUMOylation and targeted for proteasome degradation (38). Moreover, SUMOylation preserves substrate stability by competing with ubiquitination for the lysine residue or by recruiting the SUMO-targeted ubiquitin ligase (STUBL) family of proteins to the SUMOylated substrates. SUMOylation of hyperphosphorylated tau at K340 inhibits its ubiquitylation and the subsequent proteasome-dependent degradation (39). Gao et al. showed that PKC $\delta$ was SUMOylated at lysine 473, and the SUMOylation increased PKC $\delta$ stability by repressing its ubiquitination (40). Besides, SUMOylation induces conformational changes in proteins and thereby regulates protein functions (41-43). SUMOylation of PKM2 lysine 270 (K270) triggered conformation change from tetrameric to dimeric of PKM2, and reduced PKM activity (44). Furthermore, SUMOylation provides a new mechanism to recruit proteins with SUMO-interacting motif. Blondel et al. identified a non-covalent interaction between SUMO and $\beta$-arr2, via a SUMO interaction motif (SIM), that is, required for $\beta$-arr2 cytonuclear trafficking (45). Thus, SUMOylation and
de-SUMOylation coordinate the regulation of various cellular signaling pathways (42).

\section{SUMOylation in Cardiovascular Disease}

SUMOylation is an important PTM in the regulation of cell division, DNA repair, genetic and epigenetic transcriptional regulation, and cellular metabolism $(4,14,20)$. Consequently, dysregulation of SUMOylation is closely related to the pathogenesis of various diseases, such as cancer, diabetes, epilepsy, and cardiovascular diseases $(46,47)$. Many recent studies suggest that SUMOylation is a therapeutic target in the cardiovascular system. Importantly, SUMOylation not only affects cardiac function and development (11, 48-50) but also controls the capacity of the heart to adapt to various pathological stresses (51) (Figure 2). Specific SUMO isoforms (e.g., SUMO1, 2, 3) are required and play a different role in the heart. SUMO-1 KO mice suffered from congenital heart diseases such as atrial and septal defects, progressive cardiac dysfunction and sudden death (52). Specifically, the over-expression of SUMO1 enhances cardiac function in mice with heart failure and increases contractility in isolated cardiomyocytes (10). SUMO-2 KO mice exhibited severe developmental delay, without any specific cardiac phenotype, and died at embryonic stage E10.5 
TABLE 1 | Key enzymes in the SUMO pathway.

\begin{tabular}{|c|c|c|c|c|c|c|}
\hline Category & Name & $\begin{array}{l}\text { Molecular } \\
\text { weights }\end{array}$ & Cellular location & $\begin{array}{l}\text { Isoform } \\
\text { preference }\end{array}$ & Function & State of SUMO pathway \\
\hline \multirow[t]{3}{*}{ SENPS } & SENP1 & $73.5 \mathrm{kDa}$ & Cytoplasm, nucleus & All SUMO & Maturation & SUMOylation \\
\hline & SENP2 & $67.8 \mathrm{kDa}$ & Cytoplasm, nucleus & All SUMO & & \\
\hline & SENP5 & $86.7 \mathrm{kDa}$ & Nucleus (almost) & All SUMO & & \\
\hline \multirow[t]{2}{*}{ SUMO E1 } & SAE1 & $38.5 \mathrm{kDa}$ & Nucleus (almost) & All SUMO & Activation & SUMOylation \\
\hline & SAE2 & $71.2 \mathrm{kDa}$ & Cytoplasm, nucleus & & & \\
\hline SUMO E2 & UBC9 & $18.0 \mathrm{kDa}$ & Nucleus (almost) & All SUMO & Conjugation & SUMOylation \\
\hline \multirow[t]{16}{*}{ SUMO E3 } & PIAS1 & $71.8 \mathrm{kDa}$ & Nucleus (almost) & All SUMO & Ligation & SUMOylation \\
\hline & PIAS3 & $68.0 \mathrm{kDa}$ & Cytoplasm, nucleus & & & \\
\hline & PIASy & $56.5 \mathrm{kDa}$ & Nucleus & & & \\
\hline & RanBP2 & $358.2 \mathrm{kDa}$ & Nucleus & & & \\
\hline & MAPL & $39.8 \mathrm{kDa}$ & Mitochondrion & & & \\
\hline & Pc2/CBX4 & $61.4 \mathrm{kDa}$ & Nucleus & & & \\
\hline & Smc5/6 & 128.8 kDa & Nucleus & & & \\
\hline & ZNF451 & $121.5 \mathrm{kDa}$ & Nucleus & & & \\
\hline & Topors & $119.2 \mathrm{kDa}$ & Nucleus & & & \\
\hline & ZIP3 & $33.6 \mathrm{kDa}$ & Nucleus & & & \\
\hline & Rhes & $30.4 \mathrm{kDa}$ & Cell membrane & & & \\
\hline & KAP1 & $18.2 \mathrm{kDa}$ & Cytoskeleton & & & \\
\hline & NSE2 & $27.9 \mathrm{kDa}$ & Nucleus & & & \\
\hline & *SLX5/STUbLs & $71.2 \mathrm{kDa}$ & Nucleus & & & \\
\hline & *SIZ1 & $100.8 \mathrm{kDa}$ & Cytoplasm, nucleus & & & \\
\hline & *SIZ2 & $81.2 \mathrm{kDa}$ & Nucleus & & & \\
\hline \multirow[t]{6}{*}{ SENPS } & SENP1 & $73.5 \mathrm{kDa}$ & Cytoplasm, nucleus & All SUMO & Deconjugation & deSUMOylation \\
\hline & SENP2 & $67.8 \mathrm{kDa}$ & Cytoplasm, nucleus & All SUMO & & \\
\hline & SENP3 & $65.0 \mathrm{kDa}$ & Nucleus (almost) & SUMO2/3 & & \\
\hline & SENP5 & $86.7 \mathrm{kDa}$ & Nucleus (almost) & SUMO2/3 & & \\
\hline & SENP6 & $126.1 \mathrm{kDa}$ & Nucleus (almost) & SUMO2/3 & & \\
\hline & SENP7 & 119.7 kDa & Cytoplasm, nucleus ${ }^{\#}$ & SUMO2/3 & & \\
\hline
\end{tabular}

*Specific for yeast while the others are present in human.

\# In human cell, a majority of SENP7 was localized in nuclei whereas in mouse and rabbit cells, most SENP7 was distributed in the cytoplasm (27).

whereas SUMO-3 KO mice were viable (53). Another study showed that the dynamics of the SUMOylation/deSUMOylation was altered during MI/R injury correlating with the decrease in SENPs activities, especially that of SENP3 (54). Presumably, the SUMOylation system may control the response of the heart to hypoxic/ischemic stress (55). Nevertheless, little is known about the regulation of the SUMOylation system and the potential target proteins during MI.

\section{SUMOYLATION IN THE PATHOPHYSIOLOGICAL PROCESS OF MYOCARDIAL INFARCTION}

MI occurs when blood supply to the heart is initially restricted. Upon the restoration of blood flow, the myocardial tissues receive concomitant reoxygenation. However, ischemia causes initial injury while reperfusion further exacerbates inflammatory responses in cardiac tissues (56). Thus, the ischemia-reperfusion injury consolidates the myocardial injury in two different pathophysiological states: ischemia and subsequent reperfusion (57-59).

\section{Ischemic State}

Myocardial ischemia is caused by a decrease in coronary blood flow or failure to meet the demand of cardiac tissue for oxygen. Ischemia indicates that the environment oxygen is not enough to maintain the oxidative phosphorylation in the mitochondria (60). During ischemia, anaerobic glycolysis of glucose produces excessive lactic acid in the ischemic cells and ultimately causes acidification in the heart (61). When oxidative phosphorylation is not supported by sufficient oxygen, ATP production is largely reduced, leading to the dysfunction of $\mathrm{Na}^{+}-\mathrm{K}^{+}$-ATPase and the elevation of intracellular calcium, sodium, and hydrogen concentration $(62,63)$. Subsequently, cells swell while the activities of cytoplasmic enzymes are impaired. Prolonged ischemia causes progressive and irreversible injury in the heart. Morphologically, such irreversible injury is characterized by glycogen depletion, margination of nuclear chromatin, mitochondrial swelling, and sarcolemma breaks (64). 


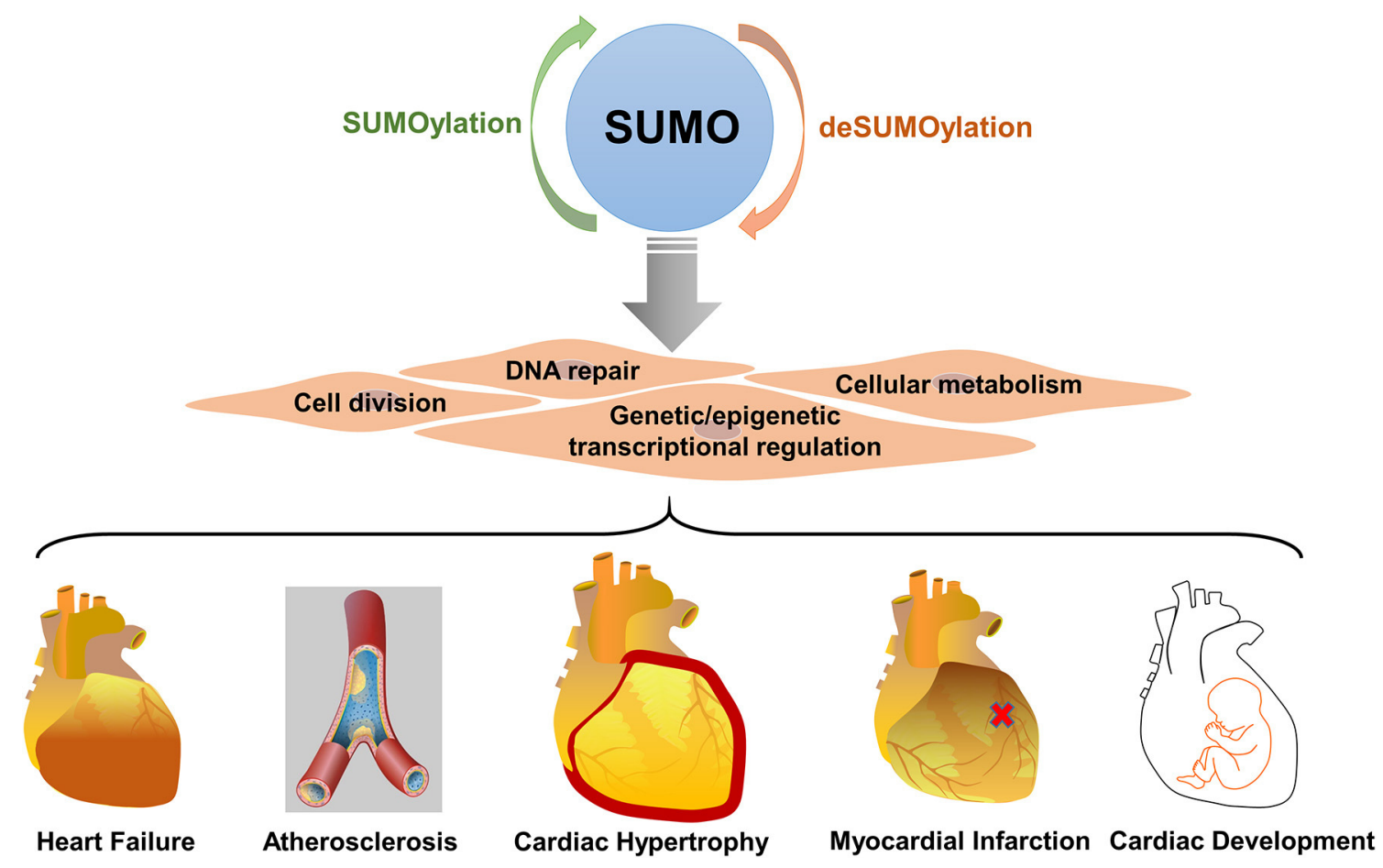

FIGURE 2 | SUMOylation plays important role in cardiovascular disease. SUMOylation regulates multiple biological processes, including cell division, DNA repair, genetic and epigenetic transcriptional regulation, and cellular metabolism in the cardiovascular system. SUMOylation is dysregulated in heart failure, atherosclerosis, cardiac hypertrophy, myocardial infarction.

\section{Reperfusion State}

Timely and complete reperfusion is critical to limit infarct size and subsequent ventricular remodeling (65). Reperfusion also causes irreversible injury to the myocardium and the coronary circulation, contributing to final infarct size $(66,67)$. During reperfusion, the mitochondrial permeability transition pore opening is triggered by multiple factors including mitochondrial calcium. Subsequently, oxidative stress and calcium overload increase the release of cytochrome $\mathrm{C}$ and thereby induce myocardial injury (68). Reperfusion not only salvages ischemic myocardium from infarction but also induces irreversible injury, leading to increased infarct size and microvascular dysfunction $(69,70)$.

Myocardial ischemia-reperfusion (MI/R) injury is a complex pathological process involving several signaling pathways (71, 72). As a key type of PTM, SUMOylation and deSUMOylation appear to affect different mechanisms toward cardiac damage. Several studies suggest that SUMOylation determines the fate of perfused hearts $(73,74)$. Ischemia increased SUMOylation levels, especially involving SUMO-2/3, while reperfusion further increased SUMOylation of various proteins in animal models and cell culture systems (75). For example, SUMO-2/3 conjugation was increased in failing human hearts (11). SUMOylation levels by SUMO-1 and SUMO-2/3 showed apparent differences in the mouse and rat models of ischemia-reperfusion injury $(76,77)$. In rats, a dramatic increase in SUMOylation by both SUMO-1 and SUMO- $2 / 3$ was observed at $6 \mathrm{~h}$ and $24 \mathrm{~h}$ in the striatal infarct area and hippocampus. In mice, no changes in SUMOylation occurred at $6 \mathrm{~h}$ but there was increased SUMO-1 conjugation in the cortical infarct after ischemia-reperfusion injury. Collectively, attention should be directed to the increase of SUMO2/3 conjugation in MI. Further work should be designed to clarify whether SUMOylation occurs mainly in the process of reperfusion or the stage of initial ischemia $(41,75,78)$. Although the role of SUMOylation in MI/R injury remains elusive $(54,79,80$ ), SUMOylation may be a promising target for drug discovery against MI (30).

\section{SUMOYLATED PROTEINS IN MYOCARDIAL INFARCTION}

Proteostasis is essential for maintaining cellular function, especially for the myocardial cell with low mitotic activity. PTM is well-known to modulate protein function and fate, suggesting that PTM plays an essential role in proteostasis (81). It is not surprising that SUMOylation positively contributes to heart function and proteostasis. SUMO isoforms are functionally distinct and modify different substrates. SUMOylation by different SUMO isoforms may exhibit unique subcellular localization patterns and dynamics $(4,20)$. Although most of the SUMO proteins are present in the nucleus, SUMOylation also occurs on extra-nuclear proteins (42). Consequently, SUMOylation regulates protein functions in intro-cellular 


\section{Myocardial Infarction}

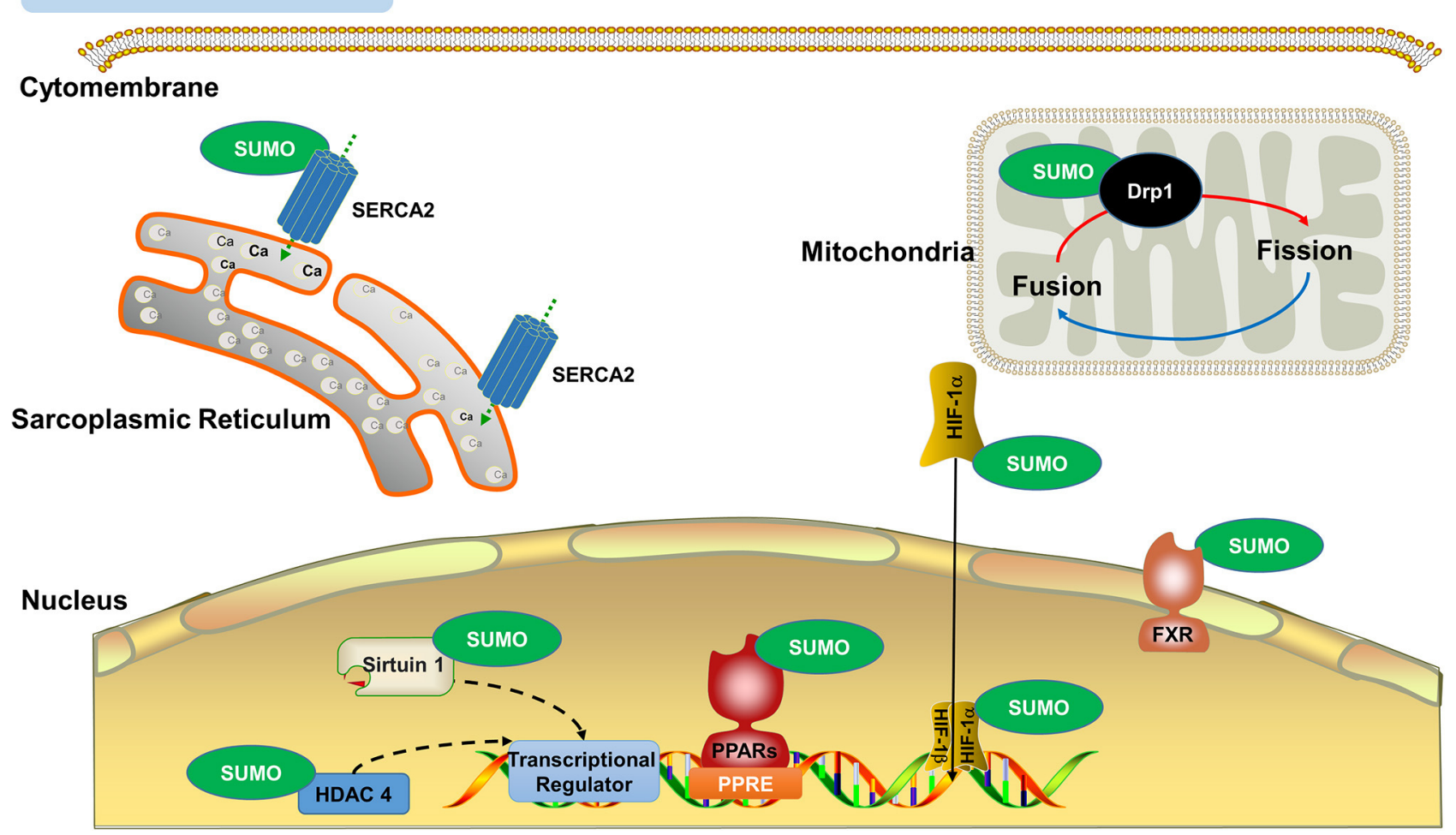

FIGURE 3 | SUMOylation regulates the functions of various proteins in myocardial infarction. SUMOylation targets include various nuclear and extranuclear proteins (e.g., Drp1, HDAC4, HIF-1 $\alpha$, PPARs, SERCA2a, Sirtuin 1) in the regulation of cardiac functions and the prevention of reactive oxygen species (ROS) and myocardial injury.

trafficking, apoptosis, protein stability, and enzyme activity (9, 33). SUMOylation and deSUMOylation coordinately affect the protein levels and thereby control the extent of MI/R injury (30). The SUMOylation of proteins is regulated by multiple signaling pathways toward the modulation of cardiac functions and development $(20,82-84)$. Other work also indicated that SUMOylation targeted the proteins that were implicated in ischemic heart disease (50). For example, SUMOylation targeted various proteins including peroxisome proliferatoractivator receptors (PPARs) (85), silent information regulator (Sirtuin) 1(86), histone deacetylase (HDAC) 4, hypoxia-inducible factor (HIF)-1 $\alpha$ (87), sarcoplasmic/endoplasmic reticulum $\mathrm{Ca}^{2+}$ ATPase2a (SERCA2a) $(8,48)$, and dynamin-related protein (Drp) 1(88). As SUMOylation plays different roles in the nucleus and the cytoplasm. The location and heart-specific functions of SUMOylated proteins are discussed in Figure 3. SUMOylation of proteins may alleviate or exacerbate myocardial damage for potential inhibitory or promoting effects $(30,80$, 89). It is well-known that SUMOylation occurs at the specific sites of target proteins. Thus, it is particularly important to identify SUMOylation sites for the development of new drugs. We employed online software GPS-SUMO (http://sumosp. biocuckoo.org/) to analyze the SUMOylation target proteins that were previously reported for direct relatedness to myocardial infarction. The predicted SUMOylation sites of the selected protein targets are listed in Table 2.

\section{SUMOylated Proteins in the Nuclear Compartment \\ Peroxisome Proliferator-Activated Receptor Isoforms- $\gamma$}

Peroxisome proliferator-activated receptors (PPARs) are ligandactivated transcription factors of the nuclear hormone receptor superfamily including three subtypes: PPAR- $\alpha, \operatorname{PPAR}-\beta / \delta$, and PPAR- $\gamma$ (90). Cellular energy expenditure is tightly controlled by the PPAR family of transcription factors exclusively in the nucleus (91). Especially, PPAR- $\gamma$ plays an important role in various physiological and pathological processes, including glucose and lipid metabolism, immunity (92). PPAR- $\gamma$ is shown to be beneficial in the treatment of cardiovascular diseases such as those related to ventricular hypertrophy, cardiac remodeling, and acute myocardial infarction $(93,94)$. Activation of PPAR$\gamma$ suppresses the inflammatory response in cardiac tissue after ischemia-reperfusion and alleviates pathological ischemic damage (95).

The activities of PPARs and associated co-regulators are regulated by PTMs, such as ubiquitylation and SUMOylation 
TABLE 2 | List of the predicted SUMOylation sites *.

\begin{tabular}{|c|c|c|c|c|c|}
\hline $\begin{array}{l}\text { Protein } \\
\text { symbol }\end{array}$ & Uniprot ID & $\begin{array}{l}\text { Sub-organelle } \\
\text { localization }\end{array}$ & SUMOylation sites & $P$-value & Pathophysiological function \\
\hline PPAR- $\gamma$ & P37231 & nuclear compartment & $\begin{array}{l}\text { QEYQSAIK }{ }^{107} \text { VEPASPP } \\
\text { FGDFMEPK }{ }^{395} \text { FEFAVKF }\end{array}$ & $\begin{array}{l}0.000 \\
0.037\end{array}$ & Suppress apoptotic and inflammatory injury \\
\hline HDAC4 & P56524 & nuclear compartment & AQAGVQVK ${ }^{559}$ QEPIESD & 0.001 & Enhance the survival of cardiomyocytes \\
\hline SIRT1 & Q96EB6 & nuclear compartment & $\begin{array}{l}\text { INEAISVK }{ }^{734} \text { QEVTDMN } \\
\text { DEPLAIMK }{ }^{408} \text { PEIVFFG } \\
\text { EQFHRAMK }{ }^{427} \text { YDKDEVD } \\
\text { DMNYPSNK }{ }^{746} \mathrm{~S}\end{array}$ & $\begin{array}{l}0.004 \\
0.014 \\
0.042 \\
0.049\end{array}$ & $\begin{array}{l}\text { Enhance the myocardial cell } \\
\text { Adaption to genotoxic stress; } \\
\text { Regulate cardiac metabolism }\end{array}$ \\
\hline FXR & P51114 & nuclear compartment & $\begin{array}{l}\text { LPPPPDIK }{ }^{56} \text { KEISEGD } \\
\text { EEKINTLK }{ }^{607} \text { EENTQEA } \\
\text { LAKVRMMK }{ }^{88} \text { GEFYIE }\end{array}$ & $\begin{array}{l}0.005 \\
0.006 \\
0.026\end{array}$ & Modulate the adverse cardiac effects of FXR \\
\hline $\mathrm{HIF}-1 \alpha$ & Q16665 & nuclear compartment & $\begin{array}{l}\text { SSLFDKLK } \mathbf{K}^{391} \text { KEPDALT } \\
\text { LNQEVALK }{ }^{477} \text { LEPNPES } \\
\text { SDMVNEFK }{ }^{532} \text { LELVEKL }\end{array}$ & $\begin{array}{l}0.002 \\
0.003 \\
0.026\end{array}$ & Lead to the degradation of $\mathrm{HIF}-1 \alpha$ \\
\hline SERCA2a & P16615 & $\begin{array}{l}\text { sarcoplasmic reticulum } \\
\text { membrane }\end{array}$ & $\begin{array}{l}\text { SVIKQLMK }{ }^{480} \text { KEFTLEF } \\
\text { EDSANFIK }{ }^{585} \text { YETNLTF }\end{array}$ & $\begin{array}{l}0.004 \\
0.005\end{array}$ & $\begin{array}{l}\text { Enhance intracellular mitochondrial membrane } \\
\text { potential and reduce cell apoptosis }\end{array}$ \\
\hline Drp1 & О00429 & mitochondria & RGMLKTSK ${ }^{597}$ AEELLAE & 0.072 & $\begin{array}{l}\text { Increase mitophagy; prevent ROS generation and } \\
\text { cell death }\end{array}$ \\
\hline
\end{tabular}

*The prediction was carried out by Software GPS-SUMO (http://sumosp.biocuckoo.org/).

in different cell types. Presumably, SUMOylation regulates the roles of PPARs in cardiomyocytes $(96,97)$. SUMOylation of PPAR- $\gamma$ at lysine 77 in the transactivation domain blocks its transcriptional activity by promoting co-repressor recruitment (98). PPAR- $\gamma$ is also SUMOylated at lysine 365, which causes PPAR- $\gamma$ to occupy the promoters of inflammatory genes and inhibit their expression in macrophages (99). The protein inhibitor of activated STAT1 (PIAS1) is a specific E3 ligase for PPAR- $\gamma$ SUMOylation in the myocardium. During the ischemiareperfusion process, PIAS1 was down-regulated so that the PPAR $\gamma$ SUMOylation was accordingly reduced. Such decline in PPAR $\gamma$ SUMOylation caused dysregulation of NF- $\kappa$ B activity and suppression of anti-apoptotic and anti-inflammatory activities, leading to exacerbation of ischemia-reperfusion injury (17).

\section{Histone Deacetylase 4}

Histone deacetylases (HDACs) constitute a family of transcriptional regulators that catalyze an important type of PTM in cardiovascular diseases. HADCs inhibitors have been reported to have a cardioprotective function partially due to the promotion of protein SUMOylation in cardiomyocytes and fibroblasts (100). An earlier study demonstrated that HDACs may promote the production of reactive oxygen species (ROS) and mitochondrial damage in the period of reperfusion (101). HDAC4 belongs to class II a group of HDACs which is an important regulator of gene expression that controls pleiotropic cellular functions (102). Previous research indicated that HDAC4 SUMOylation elicited the degradation of HDAC4, caused the suppression of HDAC activity and interrupted the cellular protective pathway (103). Another study showed that SUMOylation of HDAC4 could enhance the survival and reduce apoptosis of cardiomyocytes by decreasing lactate dehydrogenase (LDH) leakage, ratio of caspase-3-positive cells in hypoxia-reoxygenation injury (103). Interestingly,
SUMOylation of HDAC4 may also reduce the production of ROS and mitochondrial dysfunction and provide indirect protection to cardiomyocytes (30). Irisin as a recently discovered cardio-myokine could decrease the protein levels of HDAC4 and alleviate the MI/R injury through SUMOylation-dependent mechanisms (104). Thus, drugs are needed to promote HDAC4 SUMOylation against MI/R injury.

\section{Silent Information Regulator 1 (Sirtuin 1)}

Silent information regulator 1 (Sirtuin 1), a nicotinamide adenine dinucleotide (NAD)-dependent deacetylase, regulates gene expression by histone deacetylation. Recent studies demonstrated that Sirtuin 1 played an intricate role in the pathology, progression, and treatment of several diseases (105, 106). SUMOylation promoted the deacetylase activity of Sirtuin1 and enhanced the cell adaption to genotoxic stress (86). Cardiac Sirtuin 1 is mainly expressed and SUMOylated in cardiomyocyte nuclei, supporting myocardial tolerance to ischemia (107). Moreover, SUMOylation promotes Sirtuin 1 activation in ischemic preconditioning (108). The SUMOylation not only modifies Sirtuin 1 to be a cardioprotective and adaptive factor under different cardiac stress conditions but also reduces the apoptosis of myocardial cells (109-112). Yang et al. showed that reduction of Sirtuin 1 SUMOylation in response to DNA damage attenuated its HDAC activity, enhanced the activity of its proapoptotic substrates and ultimately resulted in cell death (86). ROS caused the decline of Sirtuin 1 activity and disrupted the resistance to $\mathrm{MI} / \mathrm{R}$ injury in the aged mice, possibly via affecting SUMO1 and deSUMOylase activity in the heart (113). Future work should be directed to investigate whether SUMOylation regulates the nuclear vs. cytoplasmic localization of Sirtuin 1(112) and identify which of SUMO1- and SUMO2/3 dominates the SUMOylation of Sirtuin1 in the heart. 


\section{Farnesoid-X-Receptor}

Farnesoid-X-receptor (FXR), a nuclear hormone receptor, is abundantly expressed in the liver and gastrointestinal tract and plays crucial roles in the metabolism of lipids, cholesterol, bile acid, and glucose $(114,115)$. It was previously reported that FXR was also expressed in the heart and mediated pro-apoptotic cell signals in MI/R injury (116). FXR may be SUMOylated in cardiac tissue while the level of FXR SUMOylation is downregulated during ischemia and reperfusion (117). Such decline of FXR SUMOylation increased FXR transcription activity and subsequently upregulated the expression of FXR target gene SHP, leading to intrinsic apoptosis and autophagy impairment during IR injury (118). The mutation of the SUMOylation site in the FXR sequence weakened the SUMOylation while enhanced the adverse effects of FXR in MI/R injury (118). Meanwhile, the activation of the mitochondrial apoptotic pathway and the dysfunction of the autophagy pathway were observed (118). Thus, SUMOylation is an important pathway to modulate the adverse cardiac effects of FXR in myocardial infarction.

\section{Hypoxia-Inducible Factor- $1 \alpha$}

Hypoxia-inducible factor (HIF) plays an essential role in cellular and systemic oxygen homeostasis via inducing the expression of many hypoxia-responsive genes (119). HIF- $1 \alpha$ mediates hypoxiasignaling cascade to exhibit myocardial protection in $\mathrm{MI} / \mathrm{R}$ (120). HIF- $1 \alpha$ could be SUMOylated by SUMO1, SUMO2/3 during hypoxia (121). Such changes might affect several critical regulatory pathways in mammalian cells. Interestingly, SUMO1 mediated the SUMOylation of HIF-1 $\alpha$ at Lys391 and Lys477 residues, which stabilized the protein and promoted the transcriptional activity of HIF- $1 \alpha$ during hypoxia (122). Indeed, SUMO1 and HIF-1 $\alpha$ were co-expressed and formed complex in cardiomyocytes during hypoxia stimulation (123). HIF-1 $\alpha$ is well-known to protect the heart against IR injury (124). SENP1 deconjugates SUMOylated HIF- $1 \alpha$ and prevents HIF$1 \alpha$ degradation during hypoxia. SENP1 and SENP3 catalyze deSUMOylation of HIF- $1 \alpha$ and thereby exhibit cardio-protection (125). SENP1 was up-regulated during ischemia and reperfusion, and thereby activated the HIF-1 $\alpha$ pathway, and supported its cardioprotective role (126). Cheng et al. showed that the protein level of HIF- $1 \alpha$ was significantly decreased in SENP1 $1^{-/-}$mouse embryonic cells while HIF-1 $\alpha$ target genes including VEGF and GLUT-1 were down-regulated (87). Other studies confirmed that SENP1 deficiency exacerbated myocardial injury in the experimental MI/R model via the HIF- $1 \alpha$-dependent mechanism $(87,126)$. These results revealed an essential physiological role of SENP1 in the hypoxia response through the regulation of HIF- $1 \alpha$ stability (87).

\section{SUMOylated Proteins on Sarcoplasmic Reticulum Membrane}

Sarcoplasmic reticulum (SR) $\mathrm{Ca}^{2+}$ ATPase pump (SERCA2a) is an important ATP hydrolase and highly expressed in the heart for the control of $\mathrm{Ca}^{2+}$ reuptake and replenishment to SR in excitation-contraction coupling (30). Phospholamban phosphorylation increases the ATPase activity of SERCA2a and enhanced $\mathrm{Ca}^{2+}$ transport into the endoplasmic reticulum for the next round of the contraction cycle (127). Dysregulation of SERCA2a activity and $\mathrm{Ca}^{2+}$ cycling hallmark the pathology of heart failure and may drive the development of other cardiac dysfunctions (128). A recent study found that SUMOylation of SERCA2a increased the expression and activity of SERCA2a partly through SUMO1, thus improving $\Delta \Psi \mathrm{m}$ and reducing apoptotic cells in vitro and promoting the recovery of heart function and reducing infarct size in vivo (129). Mouse SERCA2a could be SUMOylated at the sites of lysine 585, 480 and 571, whereas SUMOylation at lysine 585 enhanced SERCA2a stability $(129,130)$. The protein levels of SERCA2a, SUMO1, and the SUMOylated SERCA2a (S-SERCA2a) were decreased in myocardial injury (14). Interestingly, SUMO1 knockdown exacerbated while SUMO1 overexpression reversed the decline of SERCA2a function and SUMOylated SERCA2a $(10,129)$. Moreover, SUMO1 overexpression decreases cardiomyocyte apoptosis, reduces infarct size, and increases cardiac function (48). Collectively, SUMO1 mediated-SUMOylation of SERCA2a appears to be an important cardioprotective mechanism against MI/R injury (129).

\section{SUMOylation of Mitochondrial Protein Dynamin-Related Protein 1}

Mitochondrial dysfunction is implicated in MI/R injury (131, 132). Dynamin-related protein (Drp) 1 is an important mitochondrial protein in the regulation of mitochondrial morphology and fission (15). It was reported that SUMOylated Drp1 was the key to mediate zinc-induced cardioprotection against I/R injury, possibly via activating the mitophagy of the mitochondria and suppressing ROS production (133). SUMOylation might inhibit Drp1 translocation from the cytosol to mitochondria, maintained the mitochondrial morphology, restrained mitochondrial fission, and protected the heart against MI/R injury (134). Interestingly, SUMOylation of Drp1 prevents $M I / R$ injury, suggesting a protective mechanism against stress (80). SUMOylation of Drp1 increased mitophagy during reperfusion, leading to the prevention of ROS, myocardial apoptosis, and myocardial injury (135). With the increase in SUMO1-mediated SUMOylation of Drp1, the mitochondrial translocation of Drp1 is prevented (15). MI/R appears to increase the expression of Drp1 in mitochondria and the SUMOylations of Drp1 by both SUMO1 and SUMO2/3 (74).

On the other hand, the biological functions of SUMOylated proteins are reversed by deSUMOylation. For deSUMOylation, SENP2 removes SUMO1 from Drp1 whereas SENP3 and SENP5 remove SUMO2/3 from Drp1 $(74,136)$. SENP3 and SENP5 preferentially remove SUMO2/3 from Drp1 and inhibits SUMO2/3-induced mitochondrial translocation of Drp1(137). Pharmacological inhibition of Drp1 by mitochondrial division inhibitor-1(Mdivi-1) significantly attenuated the effects of SENP3 on mitochondrial membrane potential, mitochondrial swelling and cardiac injury (54). Others found the decrease in SUMO2/3-mediated SUMOylation of Drp1 and the reduction of mitochondrial fission level, ROS generation, 
TABLE 3 | Anti-MI Therapeutics via targeting SUMOylation.

\begin{tabular}{|c|c|c|c|c|c|}
\hline $\begin{array}{l}\text { Therapeutics/ } \\
\text { regents }\end{array}$ & $\begin{array}{l}\text { SUMOylated } \\
\text { protein/substrate }\end{array}$ & SUMO proteases & Function & Phase of research & References \\
\hline $\begin{array}{l}\text { Moderate } \\
\text { hypothermia }\end{array}$ & / & SUMO1 & $\begin{array}{l}\text { enhancing SUMOylation and } \\
\text { attenuating MI/R injury }\end{array}$ & Clinical trial & $(123)$ \\
\hline Zinc & Drp1 & / & $\begin{array}{l}\text { Regulating mitochondrial autophagy } \\
\text { and reducing } \mathrm{MI} / \mathrm{R} \text { injury }\end{array}$ & Preclinical study & $(67)$ \\
\hline Luteolin & SERCA2a & SUMO1 & Stabilizing SERCA2a & Preclinical study & $(114,115)$ \\
\hline Ginkgolic acid & PML/Pin1/TGF- $\beta 1$ & SUMO1 & Inhibiting cardiac fibrosis & Preclinical study & $(124)$ \\
\hline Irisin & HDAC4 & SUMO1 & Improving degradation of HDAC4 & Preclinical study & $(91)$ \\
\hline Mdivi-1 & Drp1 & SENP3 & $\begin{array}{l}\text { Attenuating mitochondrial abnormality } \\
\text { and cardiac injury }\end{array}$ & Preclinical study & $(65)$ \\
\hline TAK-981 & / & SUMO molecule & Inhibiting SUMOylation & Phase 1 clinical trial & $(29)$ \\
\hline PIAS1 & PPAR- $\gamma$ & SUMO E3 ligases & Inhibiting apoptosis and inflammation & Preclinical study & (86) \\
\hline
\end{tabular}

and cell death in SENP5 transgenic mice (49). Collectively, Mdivi-1 may protect the myocardium by inhibiting the SENP3 mediated-deSUMOylation pathway. These studies suggest that the balance of SUMOylation and deSUMOylation may be a potential therapeutic target for the treatment of MI.

\section{SUMOYLATION AS A POTENTIAL THERAPEUTIC TARGET}

The existing clinical therapies do not fully resolve MI/R injury in patients with coronary heart disease. The mechanism of SUMOylation has not yet been reported in clinical therapies such as vascular interventional and drug thrombolysis. But it would be a good future direction. Some basic studies have investigated the potential of SUMOylation in the therapy of $\mathrm{MI} / \mathrm{R}$ injury. As listed in Table 3, indeed, several physical methods and chemical compounds are under development to target the SUMO pathway. Moderate hypothermia significantly enhanced SUMO1-mediated SUMOylation of various target proteins in cardiomyocytes (138). These results suggested that moderate hypothermia significantly increased SUMO1 and Bcl-2 expression levels, as well as the mitochondrial membrane potential, but significantly decreased the expression levels of caspase- 3 and mitochondrial ROS. Thus, moderate hypothermia may enhance SUMOylation and attenuate myocardial H/R injury (138). SUMOylation of Drp1 regulated mitochondrial autophagy and promoted the protective effect of zinc on hypoxia-reoxygenation injury (80). During the MI/R injury, SUMO1 conjugation was inactivated while Zinc induced mitophagy via increasing Drp1 SUMO1-mediated SUMOylation to clear damaged mitochondria, control mitochondrial quality, and prevent ROS generation, ultimately reducing MI/R injury (80).

Naturally occurring bioactive components are identified from traditional Chinese medicine for further evaluation. As an example, luteolin is a plant flavonoid with profound antioxidant and immunomodulatory properties $(139,140)$. Pharmacological studies demonstrated that luteolin not only increased the phosphorylation of protein kinase B (Akt) and phospholaban (PLB) but also the sumoylation of SERCA2a, and specificity protein 1 (Sp1) (130). In addition, luteolin upregulated the expression ratio of Bcl-2/Bax, caspase-3/cleaved-Caspase3(130). A recent study demonstrated that luteolin stabilized the binding of SUMO1 to SERCA2a and preferably promoted SUMO1mediated SUMOylation of SERCA2a at the K585 site (130). Another study revealed that SUMOylation of SERCA2a was a key mechanism to support the cardioprotective activity of luteolin against MI/R injury (129). As a phenolic acid from the plant Ginkgo biloba L, ginkgolic acid inhibited protein SUMOylation by blocking the formation of the E1SUMO1 intermediate and thereby prevented cardiac fibrosis in myocardial infarction via inhibiting SUMO-1(141). On the other hand, as a recently discovered protein hormone, irisin is initially synthesized in muscles in response to exercise for regulating metabolism and energy expenditure (142, 143). It was found that irisin exhibited cardioprotective effects in myocardial hypoxia-reoxygenation via SUMOylation mediatedHDAC4 degradation (104).

Synthetic small molecules represent another category for the evaluation as MI therapy. PIAS1 is known as a specific E3 ligase for PPAR- $\gamma$ SUMOylation and reduces apoptotic and inflammatory injury by inhibiting NF- $\kappa$ B pathway after ischemia/reperfusion (17). Mdivi-1, a pharmacological inhibitor of Drp1, significantly attenuated the mitochondrial abnormality and cardiac injury in the model of overexpressing SENP3 via inhibiting Drp1 after MI/R injury (54). Moreover, the effort is made to evaluate the Drp1 inhibitor for preventing atherosclerosis in a clinical trial [ClinicalTrials.gov Identifier: NCT03980548] (33). TAK-981 inhibits the transfer of SUMO protein from E1 to E2 by binding to the C-terminal of SUMO proteins (144). Consequently, TAK-981 is tested in patients with neoplasms or lymphomas in phase 1 clinical trial [ClinicalTrials.gov Identifier: NCT03648372] (145). Collectively, as a key PTM, the potential SUMOylation should be fully explored for the development of new therapies against myocardial infarction. 


\section{CONCLUSION}

This review discussed the effects of SUMOylation on two key pathophysiological stages of MI. The SUMO proteins modify many proteins involved in different signaling pathways so that some SUMOylated proteins exhibit different expression levels and functions against MI. When more studies are available, it would be important to study the cross-talk between SUMOylation and other types of PTM. The current understanding of SUMOylation in MI is mainly based on the previous studies in the early stage of reperfusion. Future work should elucidate the SUMOylation in cardiomyocytes at the remodeling phase after reperfusion. It is positive that SUMOylation is a promising therapeutic target for the treatment of myocardial infarction.

\section{REFERENCES}

1. DALYs GBD, Collaborators H. Global, regional, and national disabilityadjusted life-years (DALYs) for 359 diseases and injuries and healthy life expectancy (HALE) for 195 countries and territories, 1990-2017: a systematic analysis for the Global Burden of Disease Study 2017. Lancet. (2018) 392:1859-922. doi: 10.1016/S0140-6736(18)32335-3

2. Virani SS, Alonso A, Benjamin EJ, Bittencourt MS, Callaway CW, Carson AP, et al. Heart disease and stroke statistics-2020 update: a report from the american heart association. Circulation. (2020) 141:e139596. doi: 10.1161/CIR.0000000000000746

3. Anderson JL, Morrow AD. Acute myocardial infarction. N Engl J Med. (2017) 376:2053-64. doi: 10.1056/NEJMra1606915

4. Lee A, Oh JG, Gorski PA, Hajjar RJ, Kho C. Post-translational modifications in heart failure: small changes, big impact. Heart Lung Circ. (2016) 25:31924. doi: 10.1016/j.hlc.2015.11.008

5. Rookyard AW, Paulech J, Thyssen S, Liddy KA, Puckeridge M, Li DK, et al. A global profile of reversible and irreversible cysteine redox post-translational modifications during myocardial ischemia/reperfusion injury and antioxidant intervention. Antioxid Redox Signal. (2021) 34:1131. doi: 10.1089/ars.2019.7765

6. Yan K, Wang K, Li P. The role of post-translational modifications in cardiac hypertrophy. J Cell Mol Med. (2019) 23:3795-807. doi: 10.1111/jcmm.14330

7. Li J, Mahata B, Escobar M, Goell J, Wang K, Khemka P, et al. Programmable human histone phosphorylation and gene activation using a CRISPR/Cas9-based chromatin kinase. Nat Commun. (2021) 12:896. doi: 10.1038/s41467-021-21188-2

8. Kho C, Lee A, Jeong D, Oh JG, Gorski PA, Fish K, et al. Small-molecule activation of SERCA2a SUMOylation for the treatment of heart failure. Nat Commun. (2015) 6:7229. doi: 10.1038/ncomms8229

9. Geiss-Friedlander R, Melchior F. Concepts in sumoylation: a decade on. Nat Rev Mol Cell Biol. (2007) 8:947-56. doi: 10.1038/nrm2293

10. Kho C, Lee A, Jeong D, Oh JG, Chaanine AH, Kizana E, et al. SUMO1dependent modulation of SERCA2a in heart failure. Nature. (2011) 477:6015. doi: 10.1038/nature10407

11. Kim EY, Zhang Y, Ye B, Segura AM, Beketaev I, Xi Y, et al. Involvement of activated SUMO-2 conjugation in cardiomyopathy. Biochim Biophys Acta. (2015) 1852:1388-99. doi: 10.1016/j.bbadis.2015.03.013

12. Gupta MK, Gulick J, Liu R, Wang X, Molkentin JD, Robbins J. Sumo E2 enzyme UBC9 is required for efficient protein quality control in cardiomyocytes. Circ Res. (2014) 115:7219. doi: 10.1161/CIRCRESAHA.115.304760

13. Vejpongsa P, Yeh TE. Wrestling with heart failure: SUMO-1 to the rescue. Circ Res. (2014) 114:1561-3. doi: 10.1161/CIRCRESAHA.114.304125

14. Oh JG, Watanabe S, Lee A, Gorski PA, Lee P, Jeong D, et al. miR-146a suppresses SUMO1 expression and induces cardiac dysfunction in maladaptive hypertrophy. Circ Res. (2018) 123:673-85. doi: 10.1161/CIRCRESAHA.118.312751

\section{AUTHOR CONTRIBUTIONS}

The manuscript was designed by WZ and JR. WZ wrote the first draft of the manuscript. JR and XZ revised the manuscript. All authors contributed to the article and approved the submitted version.

\section{FUNDING}

This work was supported by General Research Fund (GRF) grants (17146216, 17100317, and 17119619), National Natural Science Foundation of China (81701464, 81703726, and 21778046), Health and Medical Research Fund (16171751 and 17181231), Midstream Research Programme for Universities (MRP) 053/18X, and the Hong Kong Scholars Program (XJ2019055).

15. Jin JY, Wei XX, Zhi XL, Wang XH, Meng D. Drp1-dependent mitochondrial fission in cardiovascular disease. Acta Pharmacol Sin. (2021) 42:65564. doi: 10.1038/s41401-020-00518-y

16. Qiu F, Han Y, Shao X, Paulo P, Li W, Zhu M, et al. Knockdown of endogenous RNF4 exacerbates ischaemia-induced cardiomyocyte apoptosis in mice. $J$ Cell Mol Med. (2020) 24:9545-59. doi: 10.1111/jcmm.15363

17. Xie B, Liu X, Yang J, Cheng J, Gu J, Xue S. PIAS1 protects against myocardial ischemia-reperfusion injury by stimulating PPARgamma SUMOylation. BMC Cell Biol. (2018) 19:24. doi: 10.1186/s12860-018-0176-x

18. Okura T, Gong L, Kamitani T, Wada T, Okura I, Wei CF, et al. Protection against Fas/APO-1- and tumor necrosis factor-mediated cell death by a novel protein, sentrin. J Immunol. (1996) 157:4277-81.

19. Hay RT. SUMO: a history of modification. Mol Cell. (2005) 18:112. doi: 10.1016/j.molcel.2005.03.012

20. Chang HM, Yeh HET. SUMO: from bench to bedside. Physiol Rev. (2020) 100:1599-619. doi: 10.1152/physrev.00025.2019

21. Liang YC, Lee CC, Yao YL, Lai CC, Schmitz ML, Yang MW. SUMO5, a novel poly-SUMO isoform, regulates PML nuclear bodies. Sci Rep. (2016) 6:26509. doi: 10.1038/srep26509

22. Guo D, Li M, Zhang Y, Yang P, Eckenrode S, Hopkins D, et al. A functional variant of SUMO4, a new I kappa B alpha modifier, is associated with type 1 diabetes. Nat Genet. (2004) 36:837-41. doi: 10.1038/ng1391

23. Budhiraja R, Hermkes R, Muller S, Schmidt J, Colby T, Panigrahi K, et al. Substrates related to chromatin and to RNA-dependent processes are modified by Arabidopsis SUMO isoforms that differ in a conserved residue with influence on desumoylation. Plant Physiol. (2009) 149:152940. doi: $10.1104 /$ pp. 108.135053

24. Saitoh H, Hinchey J. Functional heterogeneity of small ubiquitin-related protein modifiers SUMO-1 versus SUMO-2/3. J Biol Chem. (2000) 275:62528. doi: $10.1074 /$ jbc.275.9.6252

25. Hammoudi V, Vlachakis G, Schranz ME, van den Burg AH. Whole-genome duplications followed by tandem duplications drive diversification of the protein modifier SUMO in Angiosperms. New Phytol. (2016) 211:17285. doi: 10.1111/nph.13911

26. Maejima Y, Sadoshima J. SUMOylation: a novel protein quality control modifier in the heart. Circ Res. (2014) 115:686-9. doi: 10.1161/CIRCRESAHA.114. 304989

27. Liu Y, Liu F, Wang L, Fu JL, Luo ZW, Nie Q, et al. Localization analysis of seven de-sumoylation enzymes (SENPs) in ocular cell lines. Curr Mol Med. (2018) 18:523-32. doi: 10.2174/15665240196661901121 42025

28. Celen AB, Sahin $U$. Sumoylation on its 25th anniversary: mechanisms, pathology, emerging concepts. FEBS J. (2020) 287:3110-40. doi: 10.1111/febs.15319

29. Cohen P, Tcherpakov M. Will the ubiquitin system furnish as many drug targets as protein kinases? Cell. (2010) 143:68693. doi: 10.1016/j.cell.2010.11.016 
30. Chen J, Luo Y, Wang S, Zhu H, Li D. Roles and mechanisms of SUMOylation on key proteins in myocardial ischemia/reperfusion injury. J Mol Cell Cardiol. (2019) 134:154-64. doi: 10.1016/j.yjmcc.2019. 07.009

31. Kunz K, Piller T, Muller S. SUMO-specific proteases and isopeptidases of the SENP family at a glance. J Cell Sci. (2018) 131:jcs211904. doi: $10.1242 /$ jcs. 211904

32. Hickey CM, Wilson NR, Hochstrasser M. Function and regulation of SUMO proteases. Nat Rev Mol Cell Biol. (2012) 13:755-66. doi: 10.1038/nrm3478

33. Shetty PMV, Rangrez AY, Frey N. SUMO proteins in the cardiovascular system: friend or foe? J Biomed Sci. (2020) 27:98. doi: 10.1186/s12929-020-00689-0

34. Flotho A, Melchior F. Sumoylation: a regulatory protein modification in health and disease. Annu Rev Biochem. (2013) 82:357-85. doi: 10.1146/annurev-biochem-061909-093311

35. Vertegaal AC. SUMO chains: polymeric signals. Biochem Soc Trans. (2010) 38 (Pt 1):46-9. doi: 10.1042/BST0380046

36. Henley JM, Craig TJ, Wilkinson AK. Neuronal SUMOylation: mechanisms, physiology, and roles in neuronal dysfunction. Physiol Rev. (2014) 94:124985. doi: 10.1152/physrev.00008.2014

37. Verma V, Srivastava AK, Gough C, Campanaro A, Srivastava M, Morrell $\mathrm{R}$, et al. SUMO enables substrate selectivity by mitogen-activated protein kinases to regulate immunity in plants. Proc Natl Acad Sci USA. (2021) 118:e2021351118. doi: 10.1073/pnas.2021351118

38. Waizenegger A, Urulangodi M, Lehmann CP, Reyes TAC, Saugar I, Tercero JA, et al. Mus81-Mms4 endonuclease is an Esc2-STUbL-Cullin8 mitotic substrate impacting on genome integrity. Nat Commun. (2020) 11:5746. doi: 10.1038/s41467-020-19503-4

39. Luo HB, Xia YY, Shu XJ, Liu ZC, Feng Y, Liu XH, et al. SUMOylation at K340 inhibits tau degradation through deregulating its phosphorylation and ubiquitination. Proc Natl Acad Sci USA. (2014) 111:16586-91. doi: 10.1073/pnas.1417548111

40. Gao S, Zhao X, Hou L, Ma R, Zhou J, Zhu MX, et al. The interplay between SUMOylation and phosphorylation of PKCdelta facilitates oxidative stress-induced apoptosis. FEBS J. (2021). doi: 10.1111/febs.16050

41. Guo C, Henley MJ. Wrestling with stress: roles of protein SUMOylation and deSUMOylation in cell stress response. IUBMB Life. (2014) 66:717. doi: 10.1002/iub.1244

42. Le NT, Martin JF, Fujiwara K, Abe IJ. Sub-cellular localization specific SUMOylation in the heart. Biochim Biophys Acta Mol Basis Dis. (2017) 1863:2041-55. doi: 10.1016/j.bbadis.2017.01.018

43. Schwartz RJ, Yeh TE. Weighing in on heart failure: the role of SERCA2a SUMOylation. Circ Res. (2012) 110:1989. doi: 10.1161/RES.0b013e318246f187

44. Xia L, Jiang Y, Zhang XH, Wang XR, Wei R, Qin K, et al. SUMOylation disassembles the tetrameric pyruvate kinase M2 to block myeloid differentiation of leukemia cells. Cell Death Dis. (2021) 12:101. doi: 10.1038/s41419-021-03400-9

45. Blondel-Tepaz E, Leverve M, Sokrat B, Paradis JS, Kosic M, Saha K, et al. The RanBP2/RanGAP1-SUMO complex gates beta-arrestin2 nuclear entry to regulate the Mdm2-p53 signaling axis. Oncogene. (2021) 40:224357. doi: 10.1038/s41388-021-01704-w

46. Johnson ES. Protein modification by SUMO. Annu Rev Biochem. (2004) 73:355-82. doi: 10.1146/annurev.biochem.73.011303.074118

47. Heun P. SUMOrganization of the nucleus. Curr Opin Cell Biol. (2007) 19:350-5. doi: 10.1016/j.ceb.2007.04.014

48. Lee A, Jeong D, Mitsuyama S, Oh JG, Liang L, Ikeda Y, et al. The role of SUMO-1 in cardiac oxidative stress and hypertrophy. Antioxid Redox Signal. (2014) 21:1986-2001. doi: 10.1089/ars.2014.5983

49. Kim EY, Zhang Y, Beketaev I, Segura AM, Yu W, Xi Y, et al. SENP5, a SUMO isopeptidase, induces apoptosis and cardiomyopathy. J Mol Cell Cardiol. (2015) 78:154-64. doi: 10.1016/j.yjmcc.2014.08.003

50. Mendler L, Braun T, Muller S. The ubiquitin-like SUMO system and heart function: from development to disease. Circ Res. (2016) 118:13244. doi: 10.1161/CIRCRESAHA.115.307730

51. Joung H, Kwon S, Kim KH, Lee YG, Shin S, Kwon DH, et al. Sumoylation of histone deacetylase 1 regulates MyoD signaling during myogenesis. Exp Mol Med. (2018) 50:e427. doi: 10.1038/emm.2017.236
52. Wang J, Chen L, Wen S, Zhu H, Yu W, Moskowitz IP, et al. Defective sumoylation pathway directs congenital heart disease. Birth Defects Res A Clin Mol Teratol. (2011) 91:468-76. doi: 10.1002/bdra.20816

53. Wang L, Wansleeben C, Zhao S, Miao P, Paschen W, Yang W. SUMO2 is essential while SUMO3 is dispensable for mouse embryonic development. EMBO Rep. (2014) 15:878-85. doi: 10.15252/embr.201438534

54. Gao L, Zhao Y, He J, Yan Y, Xu L, Lin N, et al. The desumoylating enzyme sentrin-specific protease 3 contributes to myocardial ischemia reperfusion injury. J Genet Genomics. (2018) 45:125-35. doi: 10.1016/j.jgg.2017.12.002

55. Hotz PW, Wiesnet M, Tascher G, Braun T, Muller S, Mendler L. Profiling the murine SUMO proteome in response to cardiac ischemia and reperfusion injury. Molecules. (2020) 25:5571. doi: 10.3390/molecules25235571

56. Toldo S, Abbate A. The NLRP3 inflammasome in acute myocardial infarction. Nat Rev Cardiol. (2018) 15:20314. doi: $10.1038 /$ nrcardio.2017.161

57. Ibanez B, Heusch G, Ovize M, Van de Werf F. Evolving therapies for myocardial ischemia/reperfusion injury. J Am Coll Cardiol. (2015) 65:145471. doi: 10.1016/j.jacc.2015.02.032

58. Basalay MV, Yellon DM, Davidson MS. Targeting myocardial ischaemic injury in the absence of reperfusion. Basic Res Cardiol. (2020) 115:63. doi: 10.1007/s00395-020-00825-9

59. Eltzschig HK, Eckle T. Ischemia and reperfusion-from mechanism to translation. Nat Med. (2011) 17:1391-401. doi: 10.1038/nm.2507

60. Gunata M, Parlakpinar H. A review of myocardial ischaemia/reperfusion injury: pathophysiology, experimental models, biomarkers, genetics and pharmacological treatment. Cell Biochem Funct. (2021) 39:190-217. doi: 10.1002/cbf.3587

61. Beltran C, Pardo R, Bou-Teen D, Ruiz-Meana M, Villena JA, FerreiraGonzalez I, et al. Enhancing glycolysis protects against ischemiareperfusion injury by reducing ROS production. Metabolites. (2020) 10:132. doi: 10.3390/metabo10040132

62. Hopp AK, Teloni F, Bisceglie L, Gondrand C, Raith F, Nowak $\mathrm{K}$, et al. Mitochondrial $\mathrm{NAD}(+)$ controls nuclear ARTD1induced ADP-ribosylation. Mol Cell. (2021) 81:340-354. e5. doi: 10.1016/j.molcel.2020.12.034

63. Dambrova M, Zuurbier CJ, Borutaite V, Liepinsh E, Makrecka-Kuka M. Energy substrate metabolism and mitochondrial oxidative stress in cardiac ischemia/reperfusion injury. Free Radic Biol Med. (2021) 165:2437. doi: 10.1016/j.freeradbiomed.2021.01.036

64. Heusch G. Myocardial ischaemia-reperfusion injury and cardioprotection in perspective. Nat Rev Cardiol. (2020) 17:773-89. doi: 10.1038/s41569-020-0403-y

65. Heusch G, Libby P, Gersh B, Yellon D, Bohm M, Lopaschuk G, et al. Cardiovascular remodelling in coronary artery disease and heart failure. Lancet. (2014) 383:1933-43. doi: 10.1016/S0140-6736(14)60107-0

66. Andrienko TN, Pasdois P, Pereira GC, Ovens MJ, Halestrap PA. The role of succinate and ROS in reperfusion injury-a critical appraisal. J Mol Cell Cardiol. (2017) 110:1-14. doi: 10.1016/j.yjmcc.2017.06.016

67. Hausenloy DJ, Yellon MD. Targeting myocardial reperfusion injury-the search continues. N Engl J Med. (2015) 373:10735. doi: 10.1056/NEJMe1509718

68. Panel M, Ahmed-Belkacem A, Ruiz I, Guichou JF, Pawlotsky JM, Ghaleh B, et al. A phenyl-pyrrolidine derivative reveals a dual inhibition mechanism of myocardial mitochondrial permeability transition pore, which is limited by its myocardial distribution. J Pharmacol Exp Ther. (2021) 376:34857. doi: 10.1124/jpet.120.000359

69. Hausenloy DJ, Botker HE, Engstrom T, Erlinge D, Heusch G, Ibanez B, et al. Targeting reperfusion injury in patients with ST-segment elevation myocardial infarction: trials and tribulations. Eur Heart J. (2017) 38:93541. doi: 10.1093/eurheartj/ehw145

70. Heusch G, Gersh JB. The pathophysiology of acute myocardial infarction and strategies of protection beyond reperfusion: a continual challenge. Eur Heart J. (2017) 38:774-84. doi: 10.1093/eurheartj/ehw224

71. Del Re DP, Amgalan D, Linkermann A, Liu Q, Kitsis NR. Fundamental mechanisms of regulated cell death and implications for heart disease. Physiol Rev. (2019) 99:1765-817. doi: 10.1152/physrev.00022.2018

72. Jovanovic A. Cardioprotective signalling: past, present and future. Eur J Pharmacol. (2018) 833:314-9. doi: 10.1016/j.ejphar.2018.06.029 
73. Karhausen J, Bernstock JD, Johnson KR, Sheng H, Ma Q, Shen $\mathrm{Y}$, et al. Ubc9 overexpression and SUMO1 deficiency blunt inflammation after intestinal ischemia/reperfusion. Lab Invest. (2018) 98:799-813. doi: 10.1038/s41374-018-0035-6

74. Shimizu Y, Lambert JP, Nicholson CK, Kim JJ, Wolfson DW, Cho $\mathrm{HC}$, et al. DJ-1 protects the heart against ischemia-reperfusion injury by regulating mitochondrial fission. J Mol Cell Cardiol. (2016) 97:5666. doi: 10.1016/j.yjmcc.2016.04.008

75. Lee YJ, Hallenbeck MJ. SUMO and ischemic tolerance. Neuromolecular Med. (2013) 15:771-81. doi: 10.1007/s12017-013-8239-9

76. Yang W, Sheng H, Homi HM, Warner DS, Paschen W. Cerebral ischemia/stroke and small ubiquitin-like modifier (SUMO) conjugationa new target for therapeutic intervention? J Neurochem. (2008) 106:98999. doi: 10.1111/j.1471-4159.2008.05404.x

77. Cimarosti H, Lindberg C, Bomholt SF, Ronn LC, Henley MJ. Increased protein SUMOylation following focal cerebral ischemia. Neuropharmacology. (2008) 54:2809. doi: 10.1016/j.neuropharm.2007.09.010

78. Yang W, Sheng H, Thompson JW, Zhao S, Wang L, Miao P, et al. Small ubiquitin-like modifier 3-modified proteome regulated by brain ischemia in novel small ubiquitin-like modifier transgenic mice: putative protective proteins/pathways. Stroke. (2014) 45:1115-22. doi: 10.1161/STROKEAHA.113.004315

79. Zhang Y, Zheng LM, Wang CX, Gu JM, Xue S. SENP3 protects H9C2 cells from apoptosis triggered by H/R via STAT3 pathway. Eur Rev Med Pharmacol Sci. (2018) 22:2778-86. doi: 10.26355/eurrev_201805_14975

80. Bian X, Xu J, Zhao H, Zheng Q, Xiao X, Ma X, et al. ZincInduced SUMOylation of Dynamin-related protein 1 protects the heart against ischemia-reperfusion injury. Oxid Med Cell Longev. (2019) 2019:1232146. doi: 10.1155/2019/1232146

81. Da Silva-Ferrada E, Ribeiro-Rodrigues TM, Rodriguez MS, Girao H. Proteostasis and SUMO in the heart. Int J Biochem Cell Biol. (2016) 79:44350. doi: 10.1016/j.biocel.2016.09.015

82. Zhang $\mathrm{X}$, Wang $\mathrm{C}$, Zhao D, Chen X, Zhang C, Zheng J, et al. Zinc deficiency induces abnormal development of the myocardium by promoting SENP5 overexpression. PLoS ONE. (2020) 15:e0242606. doi: 10.1371/journal.pone.0242606

83. Wen B, Yuan H, Liu X, Wang H, Chen S, Chen Z, et al. GATA5 SUMOylation is indispensable for zebrafish cardiac development. Biochim Biophys Acta Gen Subj. (2017) 1861:1691-701. doi: 10.1016/j.bbagen.2017.03.005

84. Zhang L, Yang TH, Li WD. Roles of SUMOylation in heart development and cardiovascular diseases. Curr Mol Med. (2017) 16:877-84. doi: 10.2174/1566524016666161223110407

85. Wadosky KM, Willis SM. The story so far: post-translational regulation of peroxisome proliferator-activated receptors by ubiquitination and SUMOylation. Am J Physiol Heart Circ Physiol. (2012) 302:H51526. doi: 10.1152/ajpheart.00703.2011

86. Yang Y, Fu W, Chen J, Olashaw N, Zhang X, Nicosia SV, et al. SIRT1 sumoylation regulates its deacetylase activity and cellular response to genotoxic stress. Nat Cell Biol. (2007) 9:1253-62. doi: 10.1038/ncb1645

87. Cheng J, Kang X, Zhang S, Yeh TE. SUMO-specific protease 1 is essential for stabilization of HIFlalpha during hypoxia. Cell. (2007) 131:58495. doi: 10.1016/j.cell.2007.08.045

88. Anderson CA, Blackstone C. SUMO wrestling with Drp1 at mitochondria. EMBO J. (2013) 32:1496-8. doi: 10.1038/emboj.2013.103

89. Wang SJ, Chen H, Tang LJ, Tu H, Liu B, Li NS, et al. Upregulation of mitochondrial E3 ubiquitin ligase 1 in rat heart contributes to ischemia/reperfusion injury. Can J Physiol Pharmacol. (2020) 98:25966. doi: 10.1139/cjpp-2019-0285

90. Fang S, Livergood MC, Nakagawa P, Wu J, Sigmund DC. Role of the peroxisome proliferator activated receptors in hypertension. Circ Res. (2021) 128:1021-39. doi: 10.1161/CIRCRESAHA.120.318062

91. Ferre P. The biology of peroxisome proliferator-activated receptors: relationship with lipid metabolism and insulin sensitivity. Diabetes. (2004) 53 (Suppl 1):S43-50. doi: 10.2337/diabetes.53.2007.S43

92. Ahmadian M, Suh JM, Hah N, Liddle C, Atkins AR, Downes M, et al. PPARgamma signaling and metabolism: the good, the bad and the future. Nat Med. (2013) 19:557-66. doi: 10.1038/nm.3159
93. Mori D, Miyagawa S, Matsuura R, Sougawa N, Fukushima S, Ueno T, et al. Pioglitazone strengthen therapeutic effect of adipose-derived regenerative cells against ischemic cardiomyopathy through enhanced expression of adiponectin and modulation of macrophage phenotype. Cardiovasc Diabetol. (2019) 18:39. doi: 10.1186/s12933-019-0829-x

94. Wang S, Dougherty EJ, Danner LR. PPARgamma signaling and emerging opportunities for improved therapeutics. Pharmacol Res. (2016) 111:7685. doi: 10.1016/j.phrs.2016.02.028

95. Mahmoud-Awny M, Attia AS, Abd-Ellah MF, El-Abhar SH. Mangiferin mitigates gastric ulcer in ischemia/reperfused rats: involvement of PPARgamma, NF-kappaB and Nrf2/HO-1 Signaling Pathways. PLoS ONE. (2015) 10:e0132497. doi: 10.1371/journal.pone.0132497

96. Pourcet B, Pineda-Torra I, Derudas B, Staels B, Glineur C. SUMOylation of human peroxisome proliferator-activated receptor alpha inhibits its transactivity through the recruitment of the nuclear corepressor NCoR. J Biol Chem. (2010) 285:5983-92. doi: 10.1074/jbc.M109.078311

97. Ohshima $\mathrm{T}$, Koga $\mathrm{H}$, Shimotohno K. Transcriptional activity of peroxisome proliferator-activated receptor gamma is modulated by SUMO-1 modification. J Biol Chem. (2004) 279:295517. doi: 10.1074/jbc.M403866200

98. Diezko R, Suske G. Ligand binding reduces SUMOylation of the peroxisome proliferator-activated receptor gamma (PPARgamma) activation function 1 (AF1) domain. PLoS ONE. (2013) 8:e66947. doi: 10.1371/journal.pone.0066947

99. Pascual G, Fong AL, Ogawa S, Gamliel A, Li AC, Perissi V, et al. A SUMOylation-dependent pathway mediates transrepression of inflammatory response genes by PPAR-gamma. Nature. (2005) 437:759-63. doi: 10.1038/nature03988

100. Blakeslee WW, Wysoczynski CL, Fritz KS, Nyborg JK, Churchill ME, McKinsey AT. Class I HDAC inhibition stimulates cardiac protein SUMOylation through a post-translational mechanism. Cell Signal. (2014) 26:2912-20. doi: 10.1016/j.cellsig.2014.09.005

101. Herr DJ, Baarine M, Aune SE, Li X, Ball LE, Lemasters JJ, et al. HDAC1 localizes to the mitochondria of cardiac myocytes and contributes to early cardiac reperfusion injury. J Mol Cell Cardiol. (2018) 114:30919. doi: 10.1016/j.yjmcc.2017.12.004

102. Vega RB, Matsuda K, Oh J, Barbosa AC, Yang X, Meadows E, et al. Histone deacetylase 4 controls chondrocyte hypertrophy during skeletogenesis. Cell. (2004) 119:555-66. doi: 10.1016/j.cell.2004.10.024

103. Du J, Zhang L, Zhuang S, Qin GJ, Zhao CT. HDAC4 degradation mediates HDAC inhibition-induced protective effects against hypoxia/reoxygenation injury. J Cell Physiol. (2015) 230:1321-31. doi: 10.1002/jcp.24871

104. Zhao YT, Wang $\mathrm{H}$, Zhang S, Du J, Zhuang S, Zhao CT. Irisin ameliorates hypoxia/reoxygenation-induced injury through modulation of histone deacetylase 4. PLoS ONE. (2016) 11:e0166182. doi: 10.1371/journal.pone.0166182

105. Chong ZZ, Shang YC, Wang S, Maiese K. SIRT1: new avenues of discovery for disorders of oxidative stress. Expert Opin Ther Targets. (2012) 16:16778. doi: $10.1517 / 14728222.2012 .648926$

106. Singh V, Ubaid S. Role of silent information regulator 1 (SIRT1) in regulating oxidative stress and inflammation. Inflammation. (2020) 43:158998. doi: 10.1007/s10753-020-01242-9

107. Hsu CP, Zhai P, Yamamoto T, Maejima Y, Matsushima S, Hariharan $\mathrm{N}$, et al. Silent information regulator 1 protects the heart from ischemia/reperfusion. Circulation. (2010) 122:217082. doi: 10.1161/CIRCULATIONAHA.110.958033

108. Nadtochiy SM, Redman E, Rahman I, Brookes SP. Lysine deacetylation in ischaemic preconditioning: the role of SIRT1. Cardiovasc Res. (2011) 89:643-9. doi: $10.1093 / \mathrm{cvr} / \mathrm{cvq} 287$

109. Kwon HS, Ott M. The ups and downs of SIRT1. Trends Biochem Sci. (2008) 33:517-25. doi: 10.1016/j.tibs.2008.08.001

110. Chong ZZ, Wang S, Shang YC, Maiese K. Targeting cardiovascular disease with novel SIRT1 pathways. Future Cardiol. (2012) 8:89100. doi: $10.2217 / \mathrm{fca} .11 .76$

111. Becatti M, Taddei N, Cecchi C, Nassi N, Nassi PA, Fiorillo C. SIRT1 modulates MAPK pathways in ischemic-reperfused cardiomyocytes. Cell Mol Life Sci. (2012) 69:2245-60. doi: 10.1007/s00018-0120925-5 
112. Yang Y, Duan W, Li Y, Jin Z, Yan J, Yu S, et al. Novel role of silent information regulator 1 in myocardial ischemia. Circulation. (2013) 128:2232-40. doi: 10.1161/CIRCULATIONAHA.113.002480

113. Li F, Zhang L, Craddock J, Bruce-Keller AJ, Dasuri K, Nguyen A, et al. Aging and dietary restriction effects on ubiquitination, sumoylation, and the proteasome in the heart. Mech Ageing Dev. (2008) 129:51521. doi: 10.1016/j.mad.2008.04.007

114. Shaik FB, Prasad DV, Narala RV. Role of farnesoid X receptor in inflammation and resolution. Inflamm Res. (2015) 64:920. doi: 10.1007/s00011-014-0780-y

115. Seok S, Fu T, Choi SE, Li Y, Zhu R, Kumar S, et al. Transcriptional regulation of autophagy by an FXR-CREB axis. Nature. (2014) 516:10811. doi: 10.1038/nature13949

116. Pu J, Yuan A, Shan P, Gao E, Wang X, Wang Y, et al. Cardiomyocyteexpressed farnesoid-X-receptor is a novel apoptosis mediator and contributes to myocardial ischaemia/reperfusion injury. Eur Heart J. (2013) 34:1834-45. doi: 10.1093/eurheartj/ehs011

117. Gao J, Shao K, Chen X, Li Z, Liu Z, Yu Z, et al. The involvement of post-translational modifications in cardiovascular pathologies: focus on SUMOylation, neddylation, succinylation, and prenylation. J Mol Cell Cardiol. (2020) 138:49-58. doi: 10.1016/j.yjmcc.2019.11.146

118. Gao Y, Zhao Y, Yuan A, Xu L, Huang X, Su Y, et al. Effects of farnesoid-Xreceptor SUMOylation mutation on myocardial ischemia/reperfusion injury in mice. Exp Cell Res. (2018) 371:301-10. doi: 10.1016/j.yexcr.2018.07.004

119. Meng X, Wielockx B, Rauner M, Bozec A. Hypoxia-inducible factors regulate osteoclasts in health and disease. Front Cell Dev Biol. (2021) 9:658893. doi: 10.3389/fcell.2021.658893

120. Chen X, Wang C, Yang P, Shi L, Wang H. Ube2s-stabilized beta-catenin protects against myocardial ischemia/reperfusion injury by activating HIFlalpha signaling. Aging. (2020) 12:5716-32. doi: 10.18632/aging.102960

121. Carbia-Nagashima A, Gerez J, Perez-Castro C, Paez-Pereda M, Silberstein S, Stalla GK, et al. RSUME. a small RWD-containing protein, enhances SUMO conjugation and stabilizes HIF-1alpha during hypoxia. Cell. (2007) 131:309-23. doi: 10.1016/j.cell.2007.07.044

122. Bae SH, Jeong JW, Park JA, Kim SH, Bae MK, Choi SJ, et al. Sumoylation increases HIF-1alpha stability and its transcriptional activity. Biochem Biophys Res Commun. (2004) 324:394-400. doi: 10.1016/j.bbrc.2004.09.068

123. Shao R, Zhang FP, Tian F, Anders Friberg P, Wang X, Sjoland $\mathrm{H}$, et al. Increase of SUMO-1 expression in response to hypoxia: direct interaction with HIF-1alpha in adult mouse brain and heart in vivo. FEBS Lett. (2004) 569:293-300. doi: 10.1016/j.febslet.2004. 05.079

124. Tekin D, Dursun AD, Xi L. Hypoxia inducible factor 1 (HIF1) and cardioprotection. Acta Pharmacol Sin. (2010) 31:108594. doi: 10.1038/aps.2010.132

125. Kang X, Li J, Zou Y, Yi J, Zhang H, Cao M, et al. PIASy stimulates HIF1alpha SUMOylation and negatively regulates HIFlalpha activity in response to hypoxia. Oncogene. (2010) 29:5568-78. doi: 10.1038/onc.2010.297

126. Gu J, Fan Y, Liu X, Zhou L, Cheng J, Cai R, et al. SENP1 protects against myocardial ischaemia/reperfusion injury via a HIFlalpha-dependent pathway. Cardiovasc Res. (2014) 104:83-92. doi: 10.1093/cvr/cvu177

127. Kranias EG, Hajjar JR. Modulation of cardiac contractility by the phospholamban/SERCA2a regulatome. Circ Res. (2012) 110:1646-60. doi: 10.1161/CIRCRESAHA.111. 259754

128. Lopez-Crisosto C, Pennanen C, Vasquez-Trincado C, Morales PE, Bravo-Sagua R, Quest AFG, et al. Sarcoplasmic reticulum-mitochondria communication in cardiovascular pathophysiology. Nat Rev Cardiol. (2017) 14:342-60. doi: 10.1038/nrcardio.2017.23

129. Du Y, Liu P, Xu T, Pan D, Zhu H, Zhai N, et al. Luteolin modulates SERCA2a leading to attenuation of myocardial ischemia/ reperfusion injury via sumoylation at lysine 585 in mice. Cell Physiol Biochem. (2018) 45:88398. doi: $10.1159 / 000487283$

130. Hu W, Xu T, Wu P, Pan D, Chen J, Chen J, et al. Luteolin improves cardiac dysfunction in heart failure rats by regulating sarcoplasmic reticulum Ca(2+)-ATPase 2a. Sci Rep. (2017) 7:41017. doi: 10.1038/srep41017

131. Shin B, Cowan DB, Emani SM, Del Nido PJ, McCully DJ. Mitochondrial transplantation in myocardial ischemia and reperfusion injury. Adv Exp Med Biol. (2017) 982:595-619. doi: 10.1007/978-3-319-55330-6_31
132. Zeng G, Liu H, Wang $H$. Amelioration of myocardial ischemiareperfusion injury by SIRT4 involves mitochondrial protection and reduced apoptosis. Biochem Biophys Res Commun. (2018) 502:1521. doi: $10.1016 /$ j.bbrc.2018.05.113

133. Hoppins S, Lackner L, Nunnari J. The machines that divide and fuse mitochondria. Annu Rev Biochem. (2007) 76:75180. doi: 10.1146/annurev.biochem.76.071905.090048

134. Din S, Mason M, Volkers M, Johnson B, Cottage CT, Wang Z, et al. Pim-1 preserves mitochondrial morphology by inhibiting dynamin-related protein 1 translocation. Proc Natl Acad Sci U S A. (2013) 110:596974. doi: $10.1073 /$ pnas. 1213294110

135. Tong M, Zablocki D, Sadoshima J. The role of Drp1 in mitophagy and cell death in the heart. J Mol Cell Cardiol. (2020) 142:13845. doi: 10.1016/j.yjmcc.2020.04.015

136. $\mathrm{Fu} \mathrm{J}$, Yu HM, Chiu SY, Mirando AJ, Maruyama EO, Cheng JG, Hsu W. Disruption of SUMO-specific protease 2 induces mitochondria mediated neurodegeneration. PLoS Genet. (2014) 10:e1004579. doi: 10.1371/journal.pgen.1004579

137. Hay RT. SUMO-specific proteases: a twist in the tail. Trends Cell Biol. (2007) 17:370-6. doi: 10.1016/j.tcb.2007.08.002

138. Chen J, Bian X, Li Y, Xiao X, Yin Y, Du X, et al. Moderate hypothermia induces protection against hypoxia/reoxygenation injury by enhancing SUMOylation in cardiomyocytes. Mol Med Rep. (2020) 22:261726. doi: $10.3892 / \mathrm{mmr} .2020 .11374$

139. Zhou XR, Ru XC, Xiao C, Pan J, Lou YY, Tang LH, et al. Sestrin2 is involved in the Nrf2-regulated antioxidative signaling pathway in luteolin-induced prevention of the diabetic rat heart from ischemia/reperfusion injury. Food Funct. (2021) 12:3562-71. doi: 10.1039/D0FO02942D

140. Maatouk M, Mustapha N, Mokdad-Bzeouich I, Chaaban H, Abed B, Iaonnou I, et al. Thermal treatment of luteolin-7-O-beta-glucoside improves its immunomodulatory and antioxidant potencies. Cell Stress Chaperones. (2017) 22:775-85. doi: 10.1007/s12192-017-0808-7

141. Qiu F, Dong C, Liu Y, Shao X, Huang D, Han Y, et al. Pharmacological inhibition of SUMO-1 with ginkgolic acid alleviates cardiac fibrosis induced by myocardial infarction in mice. Toxicol Appl Pharmacol. (2018) 345:19. doi: 10.1016/j.taap.2018.03.006

142. Zhang D, Bae C, Lee J, Lee J, Jin Z, Kang M, et al. The bone anabolic effects of irisin are through preferential stimulation of aerobic glycolysis. Bone. (2018) 114:150-60. doi: 10.1016/j.bone.2018.05.013

143. Grygiel-Gorniak B, Puszczewicz M. A review on irisin, a new protagonist that mediates muscle-adipose-bone-neuron connectivity. Eur Rev Med Pharmacol Sci. (2017) 21:4687-93.

144. Lam V, Best SR, Bruss N, Liu T, Rowland TH, Huszar D, et al. Pharmacologic inhibition of SUMO-activating enzyme (SAE) with TAK981 augments interferon signaling and regulates $\mathrm{T}$ cell differentiation in ex vivo studies of chronic lymphocytic leukemia (CLL). Blood. (2019) 134:1760. doi: 10.1182/blood-2019-127539

145. Langston SP, Grossman S, England D, Afroze R, Bence N, Bowman D, et al. Discovery of TAK-981, a first-in-class inhibitor of SUMO-activating enzyme for the treatment of cancer. J Med Chem. (2021) 64:250120. doi: 10.1021/acs.jmedchem.0c01491

Conflict of Interest: The authors declare that the research was conducted in the absence of any commercial or financial relationships that could be construed as a potential conflict of interest.

Publisher's Note: All claims expressed in this article are solely those of the authors and do not necessarily represent those of their affiliated organizations, or those of the publisher, the editors and the reviewers. Any product that may be evaluated in this article, or claim that may be made by its manufacturer, is not guaranteed or endorsed by the publisher.

Copyright $\odot 2021$ Zhao, Zhang and Rong. This is an open-access article distributed under the terms of the Creative Commons Attribution License (CC BY). The use, distribution or reproduction in other forums is permitted, provided the original author(s) and the copyright owner(s) are credited and that the original publication in this journal is cited, in accordance with accepted academic practice. No use, distribution or reproduction is permitted which does not comply with these terms. 